\title{
Article \\ Boot Swabs to Evaluate Cleaning and Disinfection Success in Poultry Barns
}

\author{
Rafael H. Mateus-Vargas ${ }^{1}$, Kira Butenholz ${ }^{1}$, Nina Volkmann ${ }^{1,2}$ (D) Christian Sürie ${ }^{3}$, Nicole Kemper ${ }^{1}$ (D) \\ and Jochen Schulz $1, *$ (D)
}

check for updates

Citation: Mateus-Vargas, R.H.; Butenholz, K.; Volkmann, N.; Sürie,

C.; Kemper, N.; Schulz, J. Boot Swabs to Evaluate Cleaning and

Disinfection Success in Poultry Barns. Agriculture 2022, 12, 57. https:// doi.org/10.3390/agriculture12010057

Academic Editor: Giancarlo Bozzo

Received: 26 November 2021

Accepted: 30 December 2021

Published: 2 January 2022

Publisher's Note: MDPI stays neutral with regard to jurisdictional claims in published maps and institutional affiliations.

Copyright: (C) 2022 by the authors. Licensee MDPI, Basel, Switzerland. This article is an open access article distributed under the terms and conditions of the Creative Commons Attribution (CC BY) license (https:// creativecommons.org/licenses/by/ $4.0 /)$.
1 Institute for Animal Hygiene, Animal Welfare and Farm Animal Behavior (ITTN), University of Veterinary Medicine Hannover, Foundation, Bischofsholer Damm 15 (Building 116), D-30173 Hannover, Germany; rafaelh.mateusvargas@gmail.com (R.H.M.-V.); kira.butenholz@tiho-hannover.de (K.B.); nina.volkmann@tiho-hannover.de (N.V.); Nicole.Kemper@tiho-hannover.de (N.K.)

2 Science and Innovation for Sustainable Poultry Production (WING), University of Veterinary Medicine Hannover, Foundation, Heinestraße 1, D-49377 Vechta, Germany

3 Lehr-Und Forschungsgut Ruthe, University of Veterinary Medicine Hannover, Foundation, Schäferberg 1, D-31157 Sarstedt, Germany; christian.suerie@tiho-hannover.de

* Correspondence: jochen.schulz@tiho-hannover.de

\begin{abstract}
Due to the relevance of cleaning and disinfection in farm hygiene management, accurate evaluation of the success of such procedures remains a fundamental challenge for producers. This study aimed to use boot swab sampling to quantify the effects of such practices in poultry barns. For this purpose, the counts of both the total and fecal indicator bacteria were detected after the application of a cleaning and disinfection protocol in identical barns that were occupied by turkeys and broilers. Boot swab samples were compared to an established agar contact plating method to evaluate disinfection success. Statistical analyses showed no correlations between the bacterial counts that were obtained with either method. In contrast to the agar contact plating method, boot swab sampling permitted the assessment of the hygienic conditions of the barn floors before and after cleaning procedures. Furthermore, according to observations with the boot swab method, factors related to the species being farmed influenced the initial bacterial loads but did not affect the effectiveness of cleaning and disinfection. Species identification by matrix-assisted laser desorption ionization-time of flight mass spectrometry (MALDI-TOF) also suggested that non-fecal bacteria grow on selective media. Further studies should validate the use of this sampling technique by comparing different cleaning and disinfection protocols.
\end{abstract}

Keywords: boot swab sampling; hygiene evaluation; total aerobic counts; Enterococci

\section{Introduction}

Routine disinfection in livestock buildings is an important hygienic measure to prevent the transmission of pathogens, zoonotic agents, or resistant bacteria from a previous flock to the next production cycle. The requisites for an effective disinfection are a thorough cleaning of animal houses followed by the proper use of disinfectant compounds [1]. For example, van Hoorebeke et al. [2] showed statistical associations between the occurrence of Salmonella spp. and the omission of dry cleaning between production rounds in different layer housing systems. Similarly, a systematic literature review determined that one of the most important reasons for recurrent contamination of broiler flocks with Campylobacter spp. was insufficient cleaning and disinfection (C \& D) during the downtime [3]. Due to the relevance of these measures in animal production systems, an assessable microbiological method should not only reveal the general success of $C \& D$ procedures but also function as a control measure to confirm that every step was performed effectively. Accurate data concerning the microbiological status at different steps of $C \& D$ activities may be 
advantageous for the animal owner who wants to check the efficiency of his own work, that of the responsible staff for $C \& D$, or that of a specialist contractor.

Currently, different methods are used to control C \& D success. However, some of these methods have been shown to be of limited use or have not yet been sufficiently evaluated. For instance, agar contact plates (ACP) were used for the verification of $C$ \& D effectiveness in European housing systems for laying hens [4,5] and to evaluate $C$ \& D of poultry houses in Belgium [6]. In contrast, this method was reported to be less suitable for quantitative examinations in broiler houses, especially for the assessment of the bacterial loads prior to cleaning and/or disinfection procedures [7]. A further option to assess the microbial contamination of surfaces in animal houses are the so-called swab methods. These techniques are based on the use of sterile materials which are moistened with a sterile buffer solution to absorb the residual dirt and microorganisms from surfaces. After sampling, these swabs can be washed out with solutions in the laboratory and, due to the possibility of using dilution series, even high bacterial loads can be accurately determined. In previous studies, cotton-, gauze-, or sponge-swab sampling was used to assess the effectiveness of different C \& D approaches in broiler [7-12] or layer houses [13]. Despite the advantages that were reported by these authors, swab sampling requires a relatively high effort, while the total area of the sampled barn floor remains very small [7]. The boot swab method may, therefore, be a more practical alternative for sampling. For instance, boot swab sampling was reported to be more sensitive than other swab methods for the detection of pathogens, such as Salmonella in turkey housing systems [14]. Similarly, Behnke et al. [15] used boot swabs to compare the prevalence of Salmonella spp. on slatted and scratch areas in different breeder chicken houses. Additionally, other authors used boot swabs to detect livestock-associated methicillin-resistant Staphylococcus aureus (LA-MRSA) on barn floors and in the vicinity of pig barns [16] and examine the presence of Mycobacterium avium ssp. paratuberculosis in the facilities of dairy herds [17]. In fact, the standard boot swab sampling is described in the official Commission Regulation (EC) No 200/2010 implementing Regulation No 2160/2003 for the monitoring of the prevalence of Salmonella in breeding chicken flocks [18]. Despite the importance of pathogen determination, monitoring of those pathogens alone is not suitable to evaluate $C \& D$ procedures in livestock housing systems, the latter because they are the focus of control programs and are consequently not always present in barns [19]. Hence, to examine and compare the effectiveness of hygiene measures in terms of reduction rates, it is necessary to target indicator microorganisms, which should be both cultivable and consistently quantifiable before and after hygiene measures. Based on the observations that were mentioned above, the boot swab sampling technique would allow a relatively quick sampling of large areas of barn floors while still providing quantitative information about the microbial load.

This study aimed to utilize a boot swab sampling method to assess the success of C \& D procedures in two identical poultry barns, each used either for broiler or turkey production. Analyses were based on the quantitative determination of the total bacteria counts and fecal indicator organisms. Further analyses were performed by comparing the bacterial loads of boot swab samples to those that were obtained with the standardized agar contact plate sampling in accordance with the Dutch model IKB (Integrale Keten Beheersing) system.

\section{Materials and Methods}

\subsection{Sampling of Animal Houses}

This study was conducted in broiler and turkey barns containing two flocks each. Both barns have been involved in poultry production for 18 years and are part of a farm that is located in Northern Germany. In this study, flock is defined as a group of birds that are housed in separated sections, but they share the same airspace. The ventilation of the sections was regulated independently. The sections of the turkey barn were naturally ventilated with curtain side walls and the birds (females, B.U.T. 6, Aviagen Turkeys Ltd., Tattenhall, UK) were fattened on concrete floors that was covered with a mixture of wood 
shavings and straw as bedding material. The broiler barns were mechanically ventilated and the animals (Ross 308, Aviagen Group, Aviagen Group, Huntsville, AL, USA) were kept on concrete floor that was covered with wood shavings. The durations of fattening periods were 33 days for broiler and 113 days on average for turkeys. The number of animals and the approximate stocking densities of the flocks at the end of the production period are given in Table 1. The stocking densities of the flocks were calculated by the average living weight arriving at the slaughterhouse divided by usable floor area.

Table 1. Number of animals for each flock, production period, and stocking density.

\begin{tabular}{|c|c|c|c|c|}
\hline Production Type & Production Period & Flock & No. of Birds & $\begin{array}{l}\text { Stocking Density } \\
\left(\mathrm{kg} / \mathrm{m}^{2}\right)\end{array}$ \\
\hline \multirow[t]{7}{*}{ Broiler } & 1 & $\mathrm{~A}$ & 7771 & 32.5 \\
\hline & & B & 7889 & 32.9 \\
\hline & 2 & A & 7609 & 33.8 \\
\hline & & B & 7569 & 32.2 \\
\hline & 3 & A & 7822 & 34.0 \\
\hline & & $\mathrm{B}$ & 7858 & 33.9 \\
\hline & 4 & $\mathrm{~A}$ & 7625 & 31.0 \\
\hline \multirow[t]{6}{*}{ Turkey } & 1 & $\mathrm{~A}$ & 2083 & 44.0 \\
\hline & & B & 2125 & 47.9 \\
\hline & 2 & A & 2113 & 43.4 \\
\hline & & $\mathrm{B}$ & 2125 & 43.7 \\
\hline & 3 & A & 2101 & 48.4 \\
\hline & & B & 2127 & 47.8 \\
\hline
\end{tabular}

Immediately after each production cycle, the litter and manure were first removed with a wheel loader and subsequently removed with a stiff broom. After 1-3 days, further $C \& D$ procedures were performed by a specialist contractor. The flock compartments were cleaned and disinfected concurrently by different people in accordance with the guidelines that were given by the contractor: (1) the facilities were wetted with cold water, (2) they were hosed with water at $70{ }^{\circ} \mathrm{C}$ using high-pressure, and (3) as the floors were visually dry, disinfection was performed by spraying and fogging Aldekol Des ${ }^{\circledR} 03$ (Theseo Deutschland $\mathrm{GmbH}$, Wietmarschen, Germany) in a final concentration of 3\% to $5 \%$ and $5 \%$ to $8 \%$, respectively. The employed disinfectant product contained glutaraldehyde $(250 \mathrm{~g} / \mathrm{L})$, formaldehyde (185 g/L), and benzyl-(C12-C16)alkyldimetylammoniumchlorid (25 g/L).

The sampling plan was based on a protocol that was adapted from data that were published by Luyckx et al. [7]. Briefly, the bacteriological samples were taken from dry surfaces before the disinfection procedures (after cleaning; AC) and at least $24 \mathrm{~h}$ after disinfection but before re-population of the houses (after disinfection; AD). For boot swabs, one additional sampling was performed immediately after removing the animals, feed, and manure but before high-pressure washing (before cleaning; BC). During a one-year period, the hygienic condition of the compartments of the turkey barns was monitored three times and the broiler barns four times. The data of farm visits for sampling are given in Table 2. The temperature was measured approximately in the middle of each flock compartment at the end of each sampling time using a PCE data recorder (PCE-THB 40, PCE, Meschede, Germany). Microbiological analyses of the flock compartments were performed after all the C \& D measures, except for the last visit to the second broiler compartment that was cancelled due to logistical reasons.

\subsection{Collection and Sample Processing}

\subsubsection{Agar Contact Plate Method}

For each production round, 22 tryptic soy agar contact plates (ACP) that were supplemented with lecithin, Tween 80, and histidine (TSA-LTH; PO5172C Oxoid, Wesel, Germany) were pressed randomly onto floor surfaces at various points of each house compartment (lightly pressed for 2 to $3 \mathrm{~s}$ ). The supplemented agar was used to inactivate disinfectant 
residues from the floor. After sampling, the plate cover was fixed with Scotch tape and transported to the laboratory at $4{ }^{\circ} \mathrm{C}$. Following incubation for up to $48 \mathrm{~h}$ at $36{ }^{\circ} \mathrm{C}$, the colonies were enumerated. The contact plates had an area of $25 \mathrm{~cm}^{2}$ and, depending on the size of individual colonies, allowed a maximum count of 120 colony forming units (cfu). According to enumeration, a hygiene score between 0 and 3 was assigned to every ACP based on a modified IKB system, as shown in Table 3. Since ACPs with $>120$ cfu already give a non-accurate result, it was decided to forego the score numbers 4 and 5, which, by other authors, was given to categorize high counts (121-400 cfu) and non-countable plates [6]. Finally, arithmetic mean of the hygiene scores of the 22 sampling points was calculated to obtain the hygienogram score for each flock. Based on the hygienogram score, $C \& D$ was categorized as good (score $\leq 1.5$ ), satisfactory (score 1.6-2.9), or bad (3.0).

Table 2. Farm visit dates and correspondent mean inside temperature for sampling before wet cleaning, after wet cleaning, and after disinfection.

\begin{tabular}{cccccc}
\hline \multirow{2}{*}{$\begin{array}{c}\text { Production Type } \\
\end{array}$} & C \& D Round & Sampled Flocks & \multicolumn{2}{c}{ Visit Dates (mm.dd.yy)/Mean Inside Temperature $\left({ }^{\circ} \mathbf{C}\right)$} \\
\cline { 4 - 6 } & & & $\begin{array}{c}\text { Before Cleaning } \\
\text { (BC) }\end{array}$ & $\begin{array}{c}\text { After Cleaning } \\
\text { (AC) }\end{array}$ & $\begin{array}{c}\text { After Disinfection } \\
\text { (AD) }\end{array}$ \\
\hline Broiler & 1 & A, B & $08.28 .18 / 22.7$ & $08.31 .18 / 23.9$ & $09.4 .18 / 21.7$ \\
& 2 & A, B & $10.10 .18 / 17.7$ & $10.12 .18 / 22.6$ & $10.16 .18 / 19.3$ \\
& 3 & A, B & $04.04 .19 / 13.8$ & $04.06 .19 / 18.6$ & $04.09 .19 / 16.3$ \\
Turkey & 4 & A & $08.08 .19 / 23.4$ & $08.13 .19 / 22.3$ & $08.20 .19 / 22.3$ \\
& 1 & A, B & $05.28 .18 / 27.6$ & $06.01 .18 / 23.9$ & $06.03 .18 / 21.7$ \\
& 2 & A, B & $10.02 .18 / 13.4$ & $10.05 .18 / 20.5$ & $10.07 .18 / 12.8$ \\
& 3 & A, B & $02.12 .19 / 10.6$ & $02.14 .19 / 13.7$ & $02.17 .19 / 14.4$ \\
\hline
\end{tabular}

Table 3. Hygiene scores of compartments based on average total aerobic counts (TAC) results of 22 agar contact plates (ACP).

\begin{tabular}{cc}
\hline TAC $(\mathbf{c f u} / \mathrm{ACP})$ & Score \\
\hline 0 & 0 \\
$1-40$ & 1 \\
$41-120$ & 2 \\
$>120$ & 3 \\
\hline
\end{tabular}

\subsubsection{Boot Swab Method}

For sampling, a sterile pair of tissue boot swabs (Finnimport, Hamburg, Germany) was transferred into a sterile stomacher closure bag (Seward Ltd., United Kingdom) with $10 \mathrm{~mL}$ of sterile phosphate-buffered saline (PBS)-Tween 20 and moistened by kneading the stomacher bag several times. At the starting point inside the stable, a pair of fresh plastic over boots were pulled on using new latex gloves (Nobaglove, Wetter, Germany) before putting on the moistened boot swabs. This procedure was applied before each sampling. The flock compartments were sampled after dry cleaning (BC), after water cleaning (AC), and after disinfection (AD) by walking diagonally through the compartment. All the samples were taken by the same person who took the same number of steps after BC, AC, and $\mathrm{AD}$ in the same compartment. The length of the diagonal line of each compartment was $33.7 \mathrm{~m}$. After the last step, the boot swabs were carefully removed and placed back into the stomacher bag. The samples were immediately transferred into a cool box $\left(4^{\circ} \mathrm{C}\right)$ for transport and stored in a freezer at $4^{\circ} \mathrm{C}$ before being processed within the next $18 \mathrm{~h}$. Cooling the samples at $4{ }^{\circ} \mathrm{C}$ was practiced for comparable sample treatment and to inactivate the bactericidal effects from residues of the used disinfectants [20] which could have been potentially absorbed in the boot swab at sampling AD.

For quantitative determination, an additional $240 \mathrm{~mL}$ of sterile PBS-Tween $20(0.01 \%)$ buffer was added in the laboratory to each stomacher bag containing a pair of boot swabs. The boot samples were then homogenized for $2 \mathrm{~min}$ at $240 \mathrm{rpm}$ in a stomacher lab-blender 
(Stomacher 400 Circulator, Seward Ltd., Worthing, UK) and a dilution series was prepared. Subsequently, aliquots were spread in triplicate on tryptic soy agar (TSA) without supplements (CM0131 Oxoid, Wesel, Germany) for total aerobic counts (TAC), bile aesculin azide agar (SAFF06105 VWR, Hannover, Germany) for Enterococcus spp. (EC), and McConkey Agar No. 3 (CM0115 Oxoid, Wesel, Germany) for Enterobacteriaceae spp. (EB). The aliquots for plating were $100 \mu \mathrm{L}$ for $\mathrm{BC}$ and $\mathrm{AC}$ but $500 \mu \mathrm{L}$ for the samples that were obtained after disinfection (AD). After 24 to $48 \mathrm{~h}$ aerobic incubation at $36^{\circ} \mathrm{C}$, the colonies showing typical morphology were quantified and a weighted average was calculated. The results are reported as the number of cfu per $250 \mathrm{~mL}$ of dilution media. The detection limits were 2.92 and $2.22 \log _{10} \mathrm{cfu} 250 \mathrm{~mL}^{-1}$ per pair of boots when spread plating $100 \mu \mathrm{L}$ and $500 \mu \mathrm{L}$ aliquots directly from the original stock sample, respectively.

After quantification, three suspected EC colonies and one suspected Escherichia coli colony were isolated per sample and preserved as pure cultures in cryotubes at $-80^{\circ} \mathrm{C}$ (P730.2 Carl Roth, Karlsruhe, Germany). For identification, the isolates were further confirmed using matrix-assisted laser desorption/ionization time of flight mass spectrometry (MALDI-TOF MS). For these analyses, the isolates were streaked on Columbia Agar with sheep blood (Oxoid Deutschland $\mathrm{GmbH}$, Wesel, Germany) and incubated at $36^{\circ} \mathrm{C}$ for $24 \mathrm{~h}$. Following incubation, the isolates were analyzed using Bruker MALDI Biotyper (Bruker Daltonik GmbH, Bremen, Germany) in accordance with the protocols that were provide by manufacturer.

Additionally, for quantitative analyses, an enrichment procedure was used to increase the sensitivity of EB detection, especially for the AD samples. For this purpose, $10 \mathrm{~mL} \mathrm{sam}$ ple liquid was mixed with $90 \mathrm{~mL}$ lysogeny broth (LB) medium according to Luria/Miller (X968.1 Carl Roth, Karlsruhe, Germany) and incubated at $36{ }^{\circ} \mathrm{C}$ for $24 \mathrm{~h}$. Subsequently, $10 \mu \mathrm{L}$ was transferred with an inoculation loop from the enrichment media on McConkey agar. The inoculated plates were incubated aerobically for $24 \mathrm{~h}$ at $36^{\circ} \mathrm{C}$. To confirm the occurrence of E. coli, three suspected isolates were preserved as described above. One was examined by MALDI-TOF. If a result was negative, the remaining isolates were investigated. The detection limit of the qualitative analyses was theoretically $25 \mathrm{E}$. coli isolates per pair of boot swabs under the assumption that one culturable E. coli was present in $10 \mathrm{~mL}$ of the sample.

\subsection{Statistical Analyses}

For statistical analyses, the resulting bacterial counts (cfu $250 \mathrm{~mL}^{-1}$ ) were converted to $\log _{10}$-values. Statistical calculations were carried out using the program SAS 9.4 (SAS Institute, Inc., Cary, NC, USA). A comparison of the bacterial counts between the $C$ \& $D$ points $(B C, A C$, and $A D)$ was performed using a general linear mixed model (PROC GLIMMIX) for each poultry species and bacterial parameter. The model included the variable sampling time and compartment as fixed and random effects, respectively. The bacterial loads were furthermore compared between the poultry species at every sample time and for every parameter using the Wilcoxon rank sum test (PROC NPAR1WAY). Moreover, the final values that were obtained after disinfection by boot sampling were compared to those of the agar contact plating method by calculating Spearman's rank correlation coefficient (PROC CORR) for both poultry species separately. The results of the statistical tests were considered significant for $p<0.05$.

\section{Results}

\subsection{Agar Contact Plates}

After wet cleaning (AC), all $286(100 \%)$ ACPs that were obtained from both poultry houses were overgrown after incubation and hence not countable. In contrast, ACPs of AD sampling were partially countable and permitted a further assessment of $C \& D$ success. Based on the average IKB score, a tendency toward higher scores that were observed on the turkey stable after C \& D procedures (Table 4) was found. Furthermore, based on the average hygienogram score, C \& D was categorized four times (30.8\%) as good (score $\leq 1.5)$. 
When comparing the IKB scores between the flocks from the same barn, differences ranging between 0.18 and 0.73 were observed. The IKB scores that were obtained in this study are summarized in Table 4.

Table 4. Hygienogram scores of compartments based on the average results of the total aerobic counts that were obtained with 22 agar contact plates in each flock after disinfection.

\begin{tabular}{cccc}
\hline \multirow{2}{*}{ Production Type } & $\begin{array}{c}\text { C \& } \\
\text { Round }\end{array}$ & \multicolumn{2}{c}{ Average Hygienogram Scores } \\
\cline { 3 - 4 } & 1 & Flock A & Flock B \\
\hline Broiler & 2 & 1.9 & 1.3 \\
& 3 & 2.6 & 2.7 \\
\multirow{3}{*}{ Turkey } & $4^{1}$ & 1.2 & 1.5 \\
& 1 & 2.2 & - \\
& 2 & 3.0 & 2.6 \\
& 3 & 2.1 & 2.6 \\
\hline
\end{tabular}

${ }^{1}$ Sampling was performed only in flock A.

\subsection{Boot Swabs}

The descriptive results of the boot swabs for both animal houses are shown in Figure 1. In contrast to the ACP sampling, it was possible to determine the bacterial loads from the boot swabs at each step of the $C \& D$ procedures, including the initial bacterial load before wet cleaning $(\mathrm{BC})$. Although the surface areas of all flocks were nearly identical, the average value of the TAC at BC was clearly higher in the broiler barn $\left(10.53 \pm 0.23 \log _{10} \mathrm{cfu} 250 \mathrm{~mL}^{-1}\right)$ in comparison to the counts that were obtained from

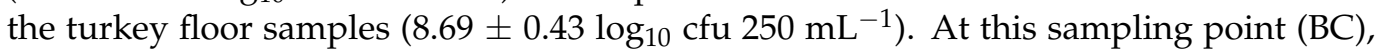
similar tendencies were also observed for the indicators EC and EB, for which the logvalues differed in average 2 and $1-\log _{10}$ units between both production species, respectively (Figure 1). According to the Wilcoxon test, the differences that were observed between poultry species were only statistically significant at sampling time BC for the three bacterial parameters (TAC: $p=0.0034$; EC: $p=0.0034$; EB: $p=0.0184$ ).

Following the dry cleaning as a result of high-pressure cleaning $(\mathrm{AC})$ and despite initial differences that are mentioned above, the bacterial loads decreased to similar levels in both production systems, especially for TAC and EC (Figure 1). Only the resulting $\log _{10}$-values of the EB counts that were obtained in the turkey stable remained at the sampling time after water cleaning (AC) on an average of over 1-fold lower than those of the broilers but with a high standard variation. According to the calculated linear mixed model, the counts of TAC, EC, and EB at AC differed significantly from those that were determined before the water cleaning $(\mathrm{BC})$ for both poultry houses $(p<0.05)$ as shown in Figure 1 . Regarding the bacterial loads at the next sampling time (after disinfection; AD), it was observed that the disinfection procedures led to a further statistically significant reduction of around 2-fold for TAC and EC (AC versus AD) in both poultry houses $(p<0.01)$. Furthermore, EB was not detected directly via the spread plating method in three of four and two of three C \& $D$ rounds of broiler and turkey, respectively. A statistical significance was determined in this case only for the broiler stable $(p=0.0022)$. Interestingly, using enrichment and despite the initial negative results, it was possible to qualitatively detect $E$. coli at AD in four further samples of each poultry house.

Irrespective of the production type, 52 and 102 colonies were isolated from samples testing positive for EB and EC, respectively. Table 5 shows the distribution of the different isolates per production type. Of note, about $70 \%$ of the strains showing characteristic morphology on bile aesculin azide agar were not confirmed as bacteria of the genus Enterococcus spp. based on MALDI-TOF. In the following, they are, therefore, referred to as aesculin splitters. Furthermore, isolates of coliforms were obtained from Mc Conkey agar and confirmed at the species level with MALDI-TOF (Table 5). 


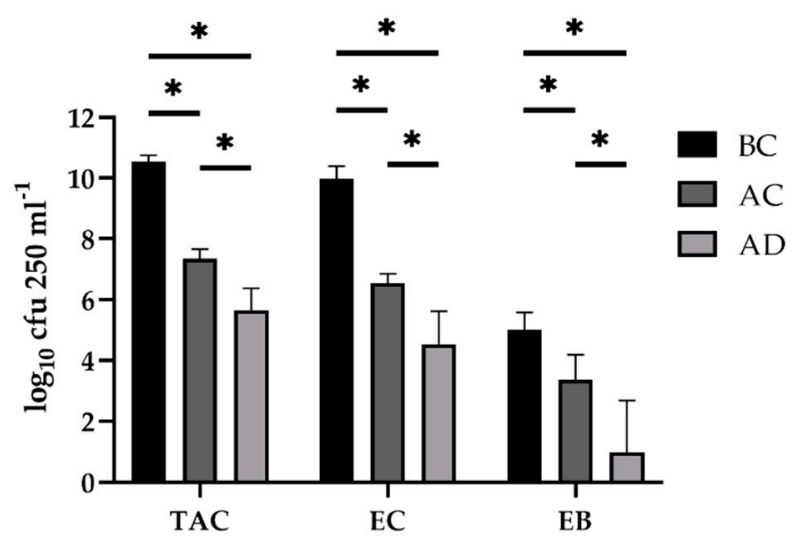

(a)

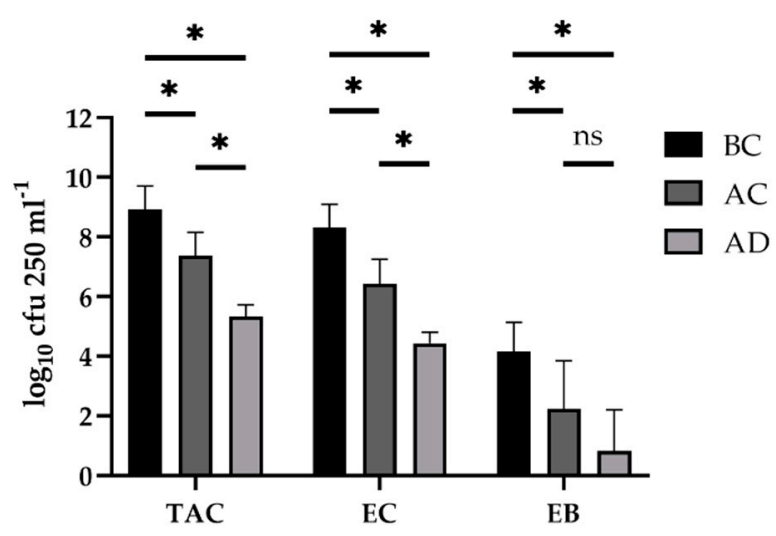

(b)

Figure 1. The means of culturable bacteria of swab samples $\left(\log _{10} \mathrm{cfu} 250 \mathrm{~mL}^{-1}\right)$ for the total aerobic counts (TAC), Enterococcus spp. (EC), and Enterobacteriaceae spp. (EB). Quantitative determination was performed at the end of the production cycles before water cleaning (BC), after water cleaning (AC), and after disinfection (AD) of poultry barns. (a) The data for the broiler barns; (b) The data for the turkey barns. For each parameter, the counts that were significantly different between the sampling times are labeled with * $(p<0.05)$. The differences without statistical significance are labeled with ns.

Table 5. Matrix-assisted laser desorption ionization-time of flight mass spectrometry (MALDI-TOF) identification of isolates that were obtained from boot swabs before water cleaning (BC), after water cleaning (AC), and after disinfection (AD) in the broiler and the turkey barns.

\begin{tabular}{|c|c|c|c|c|c|c|c|}
\hline \multirow{2}{*}{ Selective Media } & \multirow{2}{*}{$\begin{array}{l}\text { MALDI-TOF } \\
\text { Identification }\end{array}$} & \multicolumn{3}{|c|}{ Broiler } & \multicolumn{3}{|c|}{ Turkey } \\
\hline & & BC & $\mathrm{AC}$ & $\mathrm{AD}$ & BC & $\mathrm{AC}$ & $\mathrm{AD}$ \\
\hline \multirow[t]{12}{*}{ Bile aesculin azide agar } & Aerococcus viridans & & 1 & 1 & 5 & 9 & 8 \\
\hline & Alcaligenes faecalis & & & & 3 & & \\
\hline & Bacillus galactosidilyticus & & & 1 & & & 4 \\
\hline & Enterococcus casseliflavus & & 1 & 1 & & 2 & 3 \\
\hline & Enterococcus faecalis & 2 & & & & & \\
\hline & Enterococcus faecium & 1 & 2 & 1 & 2 & 1 & 1 \\
\hline & Enterococcus hirae & 1 & & & & & \\
\hline & Oceanobacillus profundus & & & & & & 2 \\
\hline & Oceanobacillus sojae & & & 2 & & & \\
\hline & $\begin{array}{c}\text { Pseudarthrobacter } \\
\text { polychromogen }\end{array}$ & 2 & & 1 & & & \\
\hline & Staphylococcus arletta & & 1 & & & & \\
\hline & Staphylococcus lentus & 3 & 1 & 1 & 3 & & \\
\hline \multirow[t]{5}{*}{ McConkey agar ${ }^{1}$} & Enterobacter cloacae & & 1 & & & & \\
\hline & Escherichia vulneris & & 1 & & & & \\
\hline & Klebsiella variicola/oxytoca & & 1 & & & & \\
\hline & Lelliottia amnigena & & & & & 3 & \\
\hline & Pantoea colida & & 1 & & & & \\
\hline
\end{tabular}

${ }^{1}$ Isolates, other than E. coli.

\subsection{Comparison of Methods}

Regarding the results of the sampling methods after disinfection (AD), while the ACP scores varied considerably between the compartments during all production cycles, the quantitative results that were obtained with boot swabs coincided relatively well during the study period. This finding is appreciable on the low standard deviation, especially for TAC and EC at every sampling point (Figure 1). When comparing the bacterial loads that 
were determined by boot swabs to those of ACPs after disinfection (AD), no significant correlations between ACP-mean counts and the TAC or the EC counts were obtained at each compartment for each $C \& D$ round of both poultry houses. The resulting correlation values are shown in Table 6.

Table 6. The correlation value and $p$-value of Spearman's rank correlation coefficients $\left(\mathrm{r}_{\mathrm{s}}\right)$ for the microbiological parameters of boot swabs and agar contact plates after disinfection.

\begin{tabular}{cccc}
\hline Production Type & Microbiological Parameter & $\mathbf{r}_{\mathbf{s}}$ & $\boldsymbol{p}$-Value \\
\hline Broiler & TAC & -0.09 & 0.57 \\
& EB & -0.21 & 0.65 \\
Turkey & TAC & -0.45 & 0.36 \\
& EB & -0.76 & 0.08 \\
\hline
\end{tabular}

\section{Discussion}

Good hygiene practices are crucial for the prevention and control of infections and pathogen transmission in livestock. The cleaning and disinfection (C \& D) of surfaces in barns between flocks is a fundamental part of the biosecurity management in poultry productions. Due to the importance of C \& D, it is furthermore required that evaluations effectively permit the detection of failures or even weaknesses at key points along the chain of C \& D procedures. Based on the observations of different studies $[8,14,16,17], C$ \& D measures were evaluated in the facilities of a poultry producer using a boot swab sampling approach. Except for the species being fattened (broiler and turkey) and the stocking densities, the surface areas as well as C \& D protocols were alike and thus comparable. The effectiveness of $C \& D$ procedures was assessed by using the traditional agar contact plating $(\mathrm{ACP})$ method and a cultural alternative using boot swab sampling. By repetitively sampling similar environmental conditions and C \& D practices, this study aimed to obtain information about the quantitative effectiveness of $C \& D$ procedures after each step in commercial poultry barns. To the best of our knowledge, this is the first report about the systematic assessment of boot swab sampling methods for the evaluation of C \& $D$ procedures using the mentioned bacteriological parameters.

The ACP method is an approach which has been well established, for instance, to routinely evaluate hygiene practices within the framework of quality systems (such as Belplume or IKB) in the animal production chain [6]. In accordance with this concept, this approach is used by extern evaluators (as the case of IKB certified farms) and may be used by herd veterinarians in their own farm control programs to assess the effectiveness of C \& D practices on the farm. Recently, this method was used by Maertens et al. [6] to evaluate the different $C$ \& D protocols and determine the key factors influencing the efficacy of disinfectants in poultry houses in Belgium. Similarly, the hygienogram score permitted the assessment of the success of the applied protocol in our study. Based on the resulting hygienograms, the $C \& D$ protocol that was used on the study farm resulted in comparable scores in the barns that were used for different poultry species although the scores tended to be slightly lower in the broiler barn. Since the barns were similarly built and managed, it would be possible to speculate that the differences in the values may be linked to biological or fattening characteristics of each poultry species. However, further enquiry about these tendencies is not possible in this case since the applied ACP method and the resulting hygienogram scores yielded no information about the initial steps of procedures and did not permit the selective evaluation of key points of C \& D. Our observations are in accordance with earlier reports in broiler houses in Belgium [7] and support the opinion that this point represents an important weakness of this cultural approach. This is especially true since the adequate conduction of cleaning procedures prior to disinfection is crucial for the final performance of the applied disinfectants $[6,8,12]$.

In contrast to the ACP method, the use of the boot swab sampling method permitted us to obtain assessable data of three different time points throughout a C \& D protocol. For instance, it was possible to observe that $C \& D$ practices in poultry houses resulted in a 
graded and statistically significant decrease in the initial aerobic bacterial load compared to the time after disinfection. In this study, the quantitative results from boot swabs showed that the cleaning procedures that were applied in the broiler barn consistently succeeded in causing a reduction in TAC and EC loads up to an order of $3 \log _{10}$. Interestingly, bacterial loads reached similar levels in both poultry barns after cleaning despite the statistically significant difference of $2 \log _{10}$ in the initial loads between both barns. In contrast to cleaning, the disinfection procedures achieved average reductions of $<2.5 \log _{10}$ for both poultry barns. These observations indicate that factors that are associated with the species being housed in the barns (such as litter material, number of animals, stocking density, or fattening time) may influence the initial hygienic conditions of the housing facilities but may not play a major role on the achievements of standardized C \& D protocols under similar conditions.

The effectiveness of C \& D in different poultry houses has been evaluated previously using other swab sampling methods in which cotton, gauze, or sponge materials were used to determine the amount of hygiene indicators in a specific area [7,8,10-12]. Due to the possibility of determining high bacterial loads, these approaches allowed the authors to recognize key factors influencing a successful C \& D procedure and to compare a diverse variety of $C \& D$ protocols and products on the studied farms. The flexibility that was offered by small swab sampling options may expand the possibilities of sampling procedures and sampled surfaces (floors, walls, drinkers, feeders, and others). On the other hand, this flexibility may also complicate comparisons between the diverse studies, especially when the methods target hygiene indicators and not specific bacteria, such as Campylobacter spp. or Salmonella spp. Despite these differences, as observed in this study and in accordance with previous reports [7,8,11,12], disinfection products achieve statistically significant bacterial load reductions when applied on farms. In addition to the use of dilution series, the samples of this study were enriched to assess the effects of the C \& D procedures on EB. This finding was of special value in this study since it permitted the qualitative evaluation of the samples for which no EB was detected by direct plating after disinfection (69\% of all AD samples). The latter result shows that fecal bacteria were still present and viable even though loads were under the limits of direct detection. This finding stresses the importance not only of the standardization of methods to perform C \& D procedures but also the value of microbiological data that are obtained throughout the C \& D practices within the framework of hygiene management in farms, especially the latter since visual cleaning inspection is not a reliable method for evaluating the hygienic conditions of poultry barns [7].

Of note, the quantitative results of the different production cycles, barns, and compartments for TAC and EC agreed relatively well throughout the study despite the C \& D procedures that were performed by different people. This finding demonstrates that boot swab sampling protocols may be standardized and allows the evaluation of C \& D practices. In our study sampling, AD was conducted at a minimum of $24 \mathrm{~h}$ after the measure to guarantee dry surfaces. Recontamination from dust during this time period cannot be completely excluded because boot swabs showed brown stain after samplings. Such recontamination may have adversely influenced the disinfection effects. On the other hand, residues from the disinfectants could have also been present in samples from the disinfected areas. The boot swabs were cooled immediately to $4{ }^{\circ} \mathrm{C}$, and samples were diluted before plating at least by factor 500 . Both measures were expected to inhibit the disinfectants that were applied in the farm $[20,21]$. Therefore, we assumed that no effects could be attributed to residues in the bacteriological results. In other studies (see Luyckx et al. [10]), neutralizers were used to avoid overestimation of the disinfection effect. However, neutralizer toxicity must be evaluated, which may be problematic if the bacterial spectrum is unknown [22]. Furthermore, other disinfectants may need other inactivation methods, such as neutralizing reagents [23]. Similar to other swab methods, a possible weaknesses of boot swabs may lead to variable outcomes concerning the quantitative evaluation of microbial indicators. For instance, the absorbency, ease of fitting, and the tensile strength 
may differ depending on the swab material [24]. Additionally, the method may be less suitable for evaluating the hygiene measures of structured floors, such as slatted ones, since only the microbial contamination on the upper surface may be recorded. A plausible factor which may influence the assessments with boot swabs is taking a different number of steps while sampling a similar distance. In this study, the sampling was, therefore, performed by a single person in all the sampled flocks and C \& D rounds to reduce the step difference effects on the quantitative results. Another important factor which may affect the accuracy of detection is the boot swab material which may also become saturated after a certain point and block further entrapment of material, thus limiting the capacity to determine high bacterial concentrations [25]. However, as observed in this study, the bacterial numbers were accurately determined up to $10.78 \log _{10} \mathrm{cfu} 250 \mathrm{~mL}^{-1}$ with this technique, which enabled measurements of possible reductions of $3 \log _{10}$ after cleaning and after disinfection from relatively large sample areas [1]. Regarding the comparison between boot swap sampling and ACP as shown in the present study and in accordance with previous evaluations of a sponge swab sampling method by Luyckx et al. [7], no correlations could be statistically confirmed between the results of ACP and those of the boot swabs. This may be due to fundamental differences of both approaches which go beyond of the total sampled area. In regard to this matter, it is important to consider that the development of colonies on agar surfaces has a close relationship with the substrate availability, which determines the number of colonies that can be counted [26]. The latter may apply, especially for samples that are taken directly from highly contaminated surfaces. Thus, the serial dilution process may theoretically result in higher numbers of cfus per area compared to those of ACP-sampling, since the lower number of cfus in the applied aliquots may have optimal conditions for sufficient development that are required for plate counting. According to Pinto et al. [27], poor and variable recovery of microorganisms from surfaces may play an important role on the reliability of the results that were obtained using ACP for environmental sampling. Such facts underline the lack of comparability of both the sampling techniques, at least under the conditions of this study.

Regarding the environmental conditions in animal barns, the indoor air temperature was reported to influence the concentration of airborne bacteria in dairy barns [28] and layer houses [29]. However, no relationships between this parameter and the bacterial loads that were measured on the surfaces of the poultry houses were observed in the present study. Since air temperature is conditioned to rapid fluctuations depending on ventilation and heating systems, the direct effect/correlation of this parameter on/with the microbial community of the barn floor is questionable, at least in the short term. Using the example of E. coli $\mathrm{O} 157$, desiccation rather than low temperatures $\left(5^{\circ} \mathrm{C}\right.$ vs. $\left.20^{\circ} \mathrm{C}\right)$ was shown to affect the survival of bacteria on surfaces [30]. In our study, the air temperature measures were performed after each sampling time to foresee possible variations on the effectiveness of cleaning and disinfection preparations that were applied in the compartments by spraying or fogging. Based on the comparable counts between the $C \& D$ rounds over the study period and despite the differences that were measured at the different sampling times, the air temperature did not seem to influence the effects of the applied substances. This may be due to the fact, that the $C \& D$ procedures were not performed below temperatures of $10{ }^{\circ} \mathrm{C}$ which could affect the antimicrobial efficiency of substances, e.g., aldehydes [1].

Further microbiological evaluations included the isolation of presumptive colonies from the selective bile aesculin azide agar or McConkey agar for further characterization by MALDI-TOF MS. As shown in Table 5, some bacterial species were isolated and confirmed at $\mathrm{AC}$ or $\mathrm{AD}$, although they were not present among the isolates that were selected at $\mathrm{BC}$. It is probable that the bacterial community shifts due to cleaning and disinfection procedures [31] may have facilitated the later detection of these microorganisms that were already present on the barn floor surfaces. Furthermore, only $30 \%$ of the colonies showing aesculin hydrolysis were identified as bacteria of the genus Enterococcus. Although most of the isolates were identified as fecal bacteria. Based on these observations, it is advisable to regard the colony count at first as a presumptive indicator and, depending on the scope of 
the evaluations, further identifications may be required, such as farm-specific biosecurity measures that are focused on persistent Enterococcosis between consecutive flocks.

\section{Conclusions}

In conclusion, boot swab sampling presents a suitable expansion of methods that are available to assess the success of $C \& D$ protocols on unstructured barn surfaces, such as concrete floors, that are commonly used in poultry barns. As shown, the sampling protocol permitted the accurate analysis of microbial dynamics throughout the C \& $D$. Theoretically, boot swab sampling may improve the efficiency of sampling of floors in terms of covered area and invested time while still providing the general advantages of the swab sampling techniques. Due to the simplicity of this sampling method, it may be carried out by veterinarians, specialist contractors, and/or even trained farm staff. By combining this technique with the possibility of enrichment and further bacterial identification with MALDI-TOF MS, it would be possible to increase both the sensitivity and specificity of the evaluations. Although ACP-sampling and boot swabs were performed under the same conditions, no correlations could be determined between the results. However, the recorded data are not enough to currently give a recommendation as to which of the two methods should be used to check the disinfection measures. Further studies should be performed to validate the use of this sampling technique by comparing C \& D protocols. It would be useful to concentrate the studies in a few barns, C \& D protocols, and/or specialist contractors to avoid the effects of variations on evaluation outcomes. Depending on the scope of the studies, it may be important to include, for instance, other swab sampling techniques and further culture and non-culture methods.

Author Contributions: Conceptualization, N.K. and J.S.; methodology, N.K., C.S. and J.S.; validation, K.B., C.S. and J.S.; formal analysis, K.B., N.V. and J.S.; resources, N.K. and J.S.; data curation, R.H.M.-V. and J.S.; writing—original draft preparation, R.H.M.-V.; writing-review and editing, N.V., C.S., N.K. and J.S.; supervision, J.S.; project administration, J.S. and N.K.; funding acquisition, N.K. and J.S. All authors have read and agreed to the published version of the manuscript.

Funding: This work was supported by the QS-Wissenschaftsfonds.

Conflicts of Interest: The authors declare no conflict of interest. The funders had no role in the design of the study; in the collection, analyses, or interpretation of data; in the writing of the manuscript, or in the decision to publish the results.

\section{References}

1. Böhm, R. Disinfection and hygiene in the veterinary field and disinfection of animal houses and transport vehicles. Int. Biodeter. Biodegr. 1998, 41, 217-224. [CrossRef]

2. $\quad$ van Hoorebeke, S.; Van Immerseel, F.; Schulz, J.; Hartung, J.; Harisberger, M.; Barco, L.; Ricci, A.; Theodoropoulos, G.; Xylouri, E.; De Vylder, J.; et al. Determination of the within and between flock prevalence and identification of risk factors for Salmonella infections in laying hen flocks housed in conventional and alternative systems. Prev. Vet. Med. 2010, 94, 94-100. [CrossRef] [PubMed]

3. Agunos, A.; Waddell, L.; Léger, D.; Taboada, E. A systematic review characterizing on-farm sources of Campylobacter spp. for broiler chickens. PLoS ONE 2014, 9, e104905. [CrossRef]

4. Huneau-Salaün, A.; Michel, V.; Balaine, L.; Petetin, I.; Eono, F.; Ecobichon, F.; Le Bouquin, S. Evaluation of common cleaning and disinfection programmes in battery cage and on-floor layer houses in France. Br. Poult Sci. 2010, 51, 204-212. [CrossRef] [PubMed]

5. De Reu, K.; Van Coillie, E.; Grijspeerdt, K.; Rodenburg, H.M.B.; Tuyttens, F.; Zoons, J.; Herman, L. Microbiological survey of furnished cages and non-cage systems for laying hens. World Poult. Sci. J. 2006, 62, 563.

6. $\quad$ Maertens, H.; De Reu, K.; Van Weyenberg, S.; Van Coillie, E.; Meyer, E.; Van Meirhaeghe, H.; Van Immerseel, F.; Vandenbroucke, V.; Vanrobaeys, M.; Dewulf, J. Evaluation of the hygienogram scores and related data obtained after cleaning and disinfection of poultry houses in Flanders during the period 2007 to 2014. Poult. Sci. 2018, 97, 620-627. [CrossRef] [PubMed]

7. Luyckx, K.; Dewulf, J.; Van Weyenberg, S.; Herman, L.; Zoons, J.; Vervaet, E.; Heyndrickx, M.; De Reu, K. Comparison of sampling procedures and microbiological and non-microbiological parameters to evaluate cleaning and disinfection in broiler houses. Poult. Sci. 2015, 94, 740-749. [CrossRef]

8. Battersby, T.; Walsh, D.; Whyte, P.; Bolton, D. Evaluating and improving terminal hygiene practices on broiler farms to prevent Campylobacter cross-contamination between flocks. Food Microbiol. 2017, 64, 1-6. [CrossRef] [PubMed] 
9. Burbarelli, M.F.C.; Polycarpo, G.V.; Lelis, K.D.; Granghelli, C.A.; Pinho, A.C.C.; Queiroz, S.R.A.; Fernandes, A.M.; Souza, R.L.M.; Moro, M.E.G.; Bordin, R.A.; et al. Cleaning and disinfection programs against Campylobacter jejuni for broiler chickens: Productive performance, microbiological assessment and characterization. Poult. Sci. 2017, 96, 3188-3198. [CrossRef] [PubMed]

10. Luyckx, K.; Van Coillie, E.; Dewulf, J.; Van Weyenberg, S.; Herman, L.; Zoons, J.; Vervaet, E.; Heyndrickx, M.; De Reu, K. Identification and biocide susceptibility of dominant bacteria after cleaning and disinfection of broiler houses. Poult. Sci. 2017, 96, 938-949. [CrossRef]

11. Luyckx, K.; Van Weyenberg, S.; Dewulf, J.; Herman, L.; Zoons, J.; Vervaet, E.; Heyndrickx, M.; De Reu, K. On-farm comparisons of different cleaning protocols in broiler houses. Poult. Sci. 2015, 94, 1986-1993. [CrossRef]

12. Ward, P.J.; Fasenko, G.M.; Gibson, S.; McMullen, L.M. A microbiological assessment of on-farm food safety cleaning methods in broiler barns. J. Appl. Poult. Res. 2006, 15, 326-332. [CrossRef]

13. Carrique-Mas, J.J.; Marin, C.; Breslin, M.; McLaren, I.; Davies, R. A comparison of the efficacy of cleaning and disinfection methods in eliminating Salmonella spp. from commercial egg laying houses. Avian Pathol. 2009, 38, 419-424. [CrossRef]

14. Mueller-Doblies, D.; Sayers, A.R.; Carrique-Mas, J.J.; Davies, R.H. Comparison of sampling methods to detect Salmonella infection of turkey flocks. J. Appl. Microbiol. 2009, 107, 635-645. [CrossRef] [PubMed]

15. Behnke, E.L.; Hofacre, C.L.; Berghaus, R.D. Estimation of the prevalence of Salmonella species on the slatted area compared to the scratch area of broiler breeder chicken houses. Avian Dis. 2013, 57, 634-639. [CrossRef] [PubMed]

16. Schulz, J.; Friese, A.; Klees, S.; Tenhagen, B.A.; Fetsch, A.; Rösler, U.; Hartung, J. Longitudinal study of the contamination of air and soil surfaces in the vicinity of pig barns by livestock-associated metichillin-resistant Staphylococcus aureus. Appl. Environ. Microbiol. 2012, 78, 5666-5671. [CrossRef]

17. Eisenberg, T.; Wolter, W.; Lenz, M.; Schlez, K.; Zschöck, M. Boot swabs to collect environmental samples from common locations in dairy herds for Mycobacterium avium ssp. paratuberculosis (MAP) detection. J. Diary Res. 2013, 80, 485-489. [CrossRef]

18. European Commission. Commission Regulation (EC) No 200/2010 of 10 March 2010 implementing Regulation (EC) No 2160/2003 of the European Parliament and of the Council as regards a Union target for the reduction of the prevalence of Salmonella serotypes in adult breeding flocks of Gallus gallus. Off. J. Eur. Union 2010, 61, 1-11.

19. Schmithausen, R.M.; Kellner, S.R.; Schulze-Geisthoevel, S.V.; Hack, S.; Engelhart, S.; Bodensetein, I.; Al-Sabti, N.; Reif, M.; Fimmers, R.; Körber-Irrgang, B.; et al. Eradication of methicillin-resistant Staphylococcus aureus and of Enterobacteriaceae expressing extended-spectrum beta-lactamases on a model pig farm. Appl. Environ. Microbiol. 2015, 81, 7633-7643. [CrossRef]

20. Gélinas, P.; Goulet, J.; Tastayre, G.M.; Picard, G.A. Effect of temperature and contact time on the activity of eight disinfectants-A classification. J. Food Protect. 1984, 47, 841-847. [CrossRef]

21. Isenberg, H.D.; Giugliano, E.R.; France, K.; Alperstein, P. Evaluation of three disinfectants after in-use stress. J. Hosp. Infect. 1988, 11, 278-285. [CrossRef]

22. Sutton, S.V.W.; Proud, D.W.; Rachui, S.; Brannan, K. Validation of microbial recovery from disinfectants. PDA J. Pharm. Sci. 2002, $56,255-266$.

23. Moore, G.; Griffith, C. Problems associated with traditional hygiene swabbing: The need for in-house standardization. J. Appl. Microbiol. 2007, 103, 1090-1103. [CrossRef]

24. Carrique-Mas, J.J.; Davies, R.H. Sampling and bacteriological detection of Salmonella in poultry and poultry premises: A review. Rev. Sci. Tech. Off. Int. Epiz. 2008, 27, 665-677. [CrossRef] [PubMed]

25. Rolfe, D.L.; Riemanm, H.P.; Farver, T.B.; Himathongkham, S. Drag swab efficiency factors when sampling manure. Avian Dis. 2000, 44, 668-675. [CrossRef] [PubMed]

26. Liu, X.; Wang, S.; Sendi, L.; Caulfield, M.J. High-throughput imaging of bacterial colonies grown on filter plates with application to serum bactericidal assays. J. Immunol. Methods 2004, 292, 187-193. [CrossRef] [PubMed]

27. Pinto, F.; Hiom, S.; Girdlestone, S.; Maillard, J.-Y. Evaluation of the effectiveness of commercially available contact plates for monitoring microbial environments. Lett. Appl. Microbiol. 2009, 48, 379-382. [CrossRef]

28. Islam, M.A.; Ikeguchi, A.; Naide, T. Concentrations of aerosol numbers and airborne bacteria, and temperature and relative humidity, and their interrelationship in a tie-stall dairy barn. Animals 2019, 9, 1023. [CrossRef]

29. Matković, K.; Vučemilo, M.; Štoković, I.; Šimić, R.; Marušić, D.; Vinković, B.; Matković, S. Concentrations of airborne bacteria and fungi in a livestock building with caged laying hens. Vet. Arhiv. 2013, 83, 413-424.

30. Williams, A.P.; Avery, L.M.; Killham, K.; Jones, D.L. Persistence of Escherichia coli O157 on farm surfaces under different environmental conditions. J. Appl. Microbiol. 2005, 98, 1075-1083. [CrossRef] [PubMed]

31. Perry-Dow, K.A.; de Man, T.J.B.; Halpin, A.L.; Shams, A.M.; Rose, L.J.; Noble-Wang, J.A. The effect of disinfectants on the microbial community on environmental healthcare surfaces using next generation sequencing. Am. J. Infect. Control 2022, 50, 54-60. [CrossRef] [PubMed] 